\title{
Clinical aspects of pulp stones: A case report series
}

\section{Aspekty kliniczne kamieni miazgi - seria przypadków}

\author{
Krystyna Pietrzycka ${ }^{A-F}$, Halina Pawlicka ${ }^{B, D, E}$ \\ Department of Endodontics, Medical University of Lodz, Poland \\ A - research concept and design; $\mathrm{B}$ - collection and/or assembly of data; $\mathrm{C}$ - data analysis and interpretation; \\ $D$ - writing the article; $E$ - critical revision of the article; $F$ - final approval of the article
}

Address for correspondence

Krystyna Pietrzycka

E-mail: krystyna.pietrzycka@umed.lodz.pl

Funding sources

None declared

Conflict of interest

None declared

Received on December 4, 2019

Reviewed on January 24,2020

Accepted on February 5, 2020

Published online on June 30, 2020

Cite as

Pietrzycka K, Pawlicka H. Clinical aspects of pulp stones: A case report series. Dent Med Probl. 2020;57(2):213-220. doi:10.17219/dmp/117944

DOI

$10.17219 / \mathrm{dmp} / 117944$

Copyright

(C) 2020 by Wroclaw Medical University

This is an article distributed under the terms of the

Creative Commons Attribution 3.0 Unported License (CC BY 3.0)

(https://creativecommons.org/licenses/by/3.0/).

\begin{abstract}
Pulp stones (PSS) are calcified masses that can be found in the pulp cavity of any deciduous or permanent tooth. They can be observed in healthy, diseased, and even unerupted or impacted teeth. Calcifications within the pulp may lead to a poorer outcome of a root canal procedure, as they can block access to the root canals, and hinder their subsequent cleaning and shaping.

The paper describes 4 clinical cases of denticles located in the coronal and radicular pulp. Therapeutic methods of PS removal with different techniques and instruments are discussed. Specialist root canal treatment (RCT) was performed in aseptic conditions with the use of long-shank rose-head burs and an endodontic ultrasonic device under the magnification of a dental operative microscope (OM). During endodontic treatment, all PSs were totally removed, which allowed the further preparation, and finally obturation of the canal system. The use of modern diagnostic and therapeutic methods - three-dimensional (3D) diagnostic radiology, endodontic techniques, such as ultrasounds used during the removal of PSs and the irrigation of the canals, and the thermoplastic methods of canal obturation - can provide good results of treatment of this pathology. The removal of PSs from the pulp cavity is a complex and difficult procedure, requiring skill, dexterity, and appropriate equipment and facilities. The clinical approach introduced in this paper allows endodontists to avoid potential complications like perforation, the unnecessary removal of hard tissues or the weakening of the tooth structure.
\end{abstract}

Key words: root canal treatment, dental operating microscope, pulp stones, denticles, ultrasonic tips

Słowa kluczowe: leczenie kanałowe, stomatologiczny mikroskop operacyjny, kamienie miazgi, zębiniaki, końcówki ultradźwiękowe 


\section{Introduction}

Pulp stones (PSs) are defined as calcified foci that are observed in the coronal or, less frequently, radicular pulp cavity. They are found in the dental pulp of the teeth in primary and permanent dentition. These calcified structures can be detected in the pulp of healthy, infected, and even impacted teeth. ${ }^{1}$ Dental pulp calcifications were mentioned for the first time in 1921 by Norman and Johnson as dental pulp nodules; this term was later modified to denticles. Kronfeld and Boyle classified pulp calcifications histologically into discrete 'true' or 'false' forms, the former containing irregular dentine and the latter being degenerative pulp calcifications. ${ }^{2}$ Other studies have proposed new classifications. Based on their size, PSs have been divided into fine and diffuse mineralization, and based on location - into embedded and free types. ${ }^{3-5}$ Pulp stones may be embedded, attached to dentin walls or free within the pulp tissue. ${ }^{6}$ The exact etiology of PS formation still remains unclear. Some factors that have been implicated in PS formation include pulp calcification, aging, orthodontic tooth movement, periodontal disease, various systemic diseases, genetic predisposition, bacterial infection, deep caries, restorations, and calcifying nanoparticles. ${ }^{7-10}$ Previous studies have reached no consensus regarding the prevalence of PSs, though reports range from $8 \%$ to $90 \%$, depending on the study type, design, and radiographic technique employed. Pulp stones may range in size from a macroscopic to microscopic mass, less than $200 \mu \mathrm{m}$, beyond radiographic resolution. The histological method of evaluation is reported to yield higher values than the radiographic method. ${ }^{11,12}$

Calcifications within the pulp may lead to a poorer outcome of a root canal procedure, as they can block access to the root canals, and hinder their subsequent cleaning and shaping. The paper describes 4 clinical cases of denticles located in the coronal and radicular pulp, and the therapeutic methods of denticle removal with different techniques and instruments.

\section{Case reports}

\section{Case 1}

A female patient, aged 28 , with no relevant medical history, was referred to the dental office for the specialist root canal treatment (RCT) of tooth 27 with a diagnosis of calcifications within the pulp and blocked access to the root canals. The previous week the tooth had been trepanned and the root canal orifices had been detected with blue dye. The clinical examination revealed no pain on percussion, no reaction of the tooth to electrical or thermal stimuli, and physiological mobility. Radiovisio- graphy (RVG) showed an extensive filling on the occlusal surface, the presence of a PS within the pulp cavity (homogenous radiopaque contrast) and a periapical lesion (Fig. 1A). A diagnosis of chronic apical periodontitis was made and antiseptic RCT was scheduled. After isolating the tooth with a rubber dam, the temporary filling was removed. The presence of an extensive PS blocking the orifice of the palatal canal was confirmed with an operating microscope (OM) (Labomed Prima DNT $^{\circledR}$; Labo America, Inc., Fremont, USA). The floor of the pulp cavity was discolored due to the application of the Canal Detector ${ }^{\circledR}$ blue dye (CERKAMED, Stalowa Wola, Poland) (Fig. 1B). The pulp cavity was prepared and the denticle was removed with the use of the BUC ${ }^{\circledR} 2$ ultrasonic tip (Obtura Spartan, Fenton, USA) and the Munce Discovery Burs ${ }^{\circledR}$ (CJM Engineering, Inc., Santa Barbara, USA). Then, the ProTaper ${ }^{\circledR}$ SX rotary file (Dentsply Sirona, Ballaigues, Switzerland) and Gates -Glidden drills (Dentsply Sirona) were applied to prepare the canal orifices. After determining the working length of the 4 canals with an apex locator, they were initially shaped with the rotary PathFiles ${ }^{\circledR}$ (Dentsply Sirona) to size 019. Due to a lack of time, an antibiotic-steroid dental paste (Dexadent ${ }^{\mathbb{R}}$; Chema-Elektromet, Rzeszów, Poland), a cotton pledget and a temporary filling $\left(\mathrm{Cavit}^{\mathbb{B}}\right.$; $3 \mathrm{M}$ ESPE, Seefeld, Germany) were applied. At the following appointment, the canals were prepared with the Mtwo $^{\circledR}$ instruments (VDW, Munich, Germany) to size 35/.04 (Fig. 1C). During the preparation, ultrasonically activated irrigation was performed with a $5.25 \% \mathrm{NaOCl}$ solution $(20 \mathrm{~mL})$ and $15 \%$ EDTA $(10 \mathrm{~mL})$ to remove the smear layer, and isopropyl alcohol (CERKAMED) was administered for a final rinse. Gutta-percha points were fitted and the canals were filled using the method of the gutta-percha continuous wave of condensation with SuperEndo ${ }^{\circledR} \alpha 2$ and SuperEndo $\beta$ (B\&L Biotech, Inc., Fairfax, USA) as well as AH Plus ${ }^{\circledR}$ (Dentsply Sirona) as a sealer. The canal orifices were secured with a flowable, colored composite material. The pulp chamber and

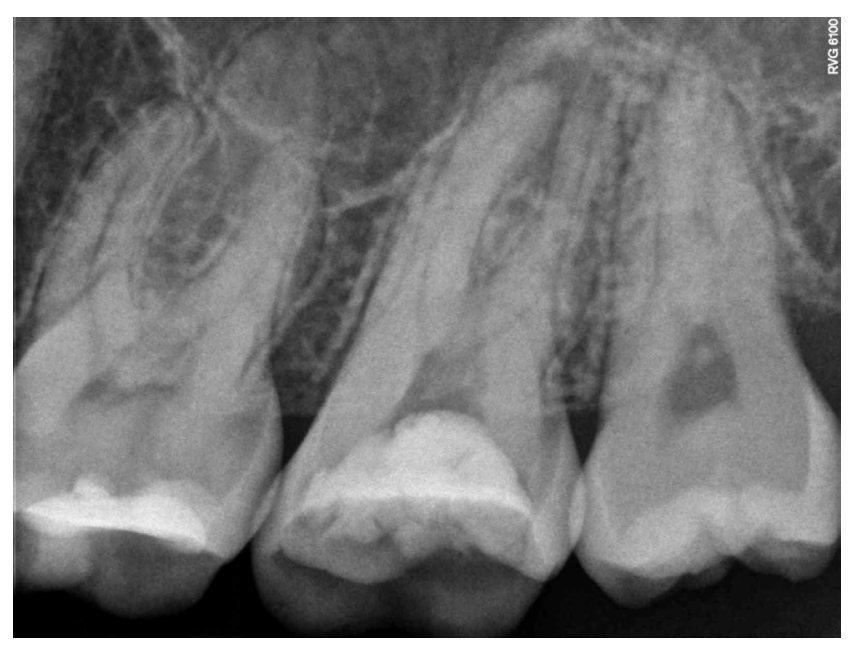

Fig. 1A. Case 1, tooth 27: Pre-operative X-ray 
the cavity were closed with glass-ionomer cement. On RVG, all canals appeared properly filled (Fig. 1D). The patient was referred for prosthetic reconstruction.

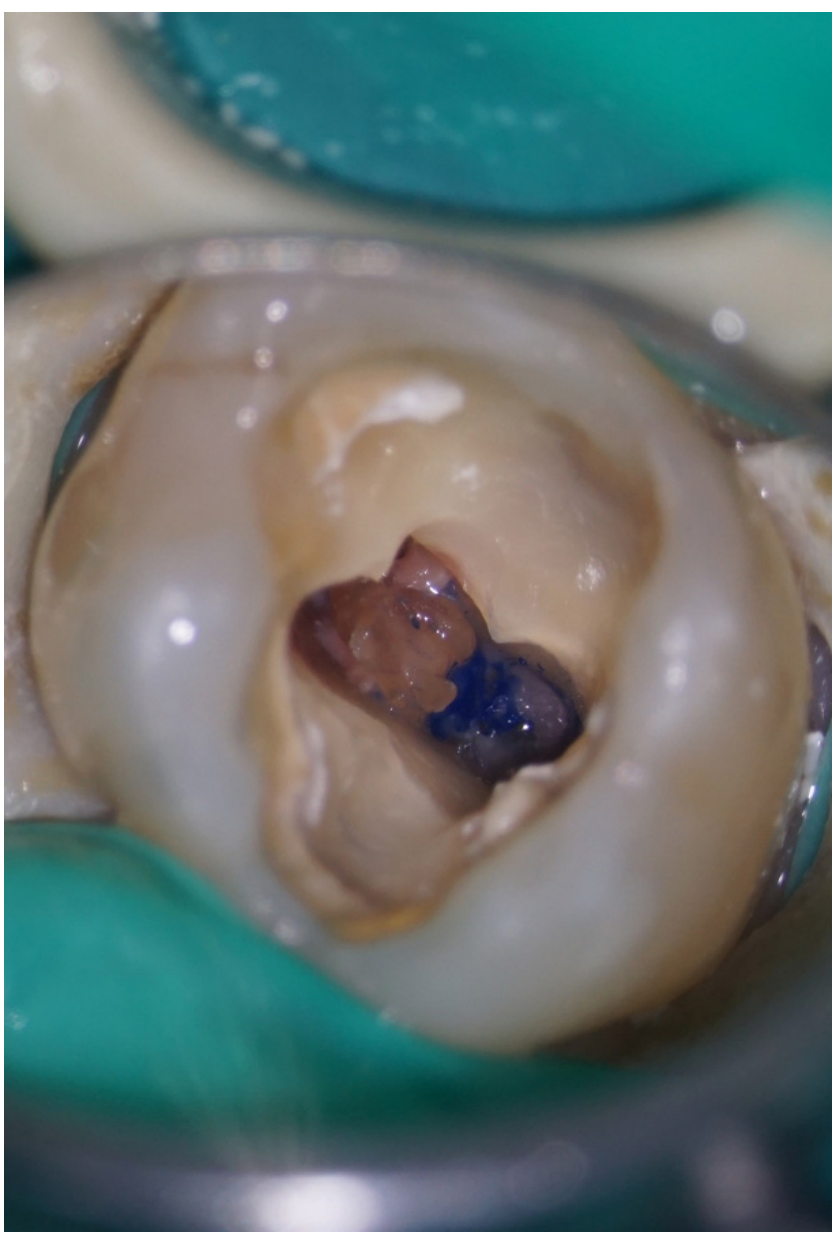

Fig. 1B. Case 1, tooth 27: Microscope-captured images of the pulp chamber floor before denticle removal

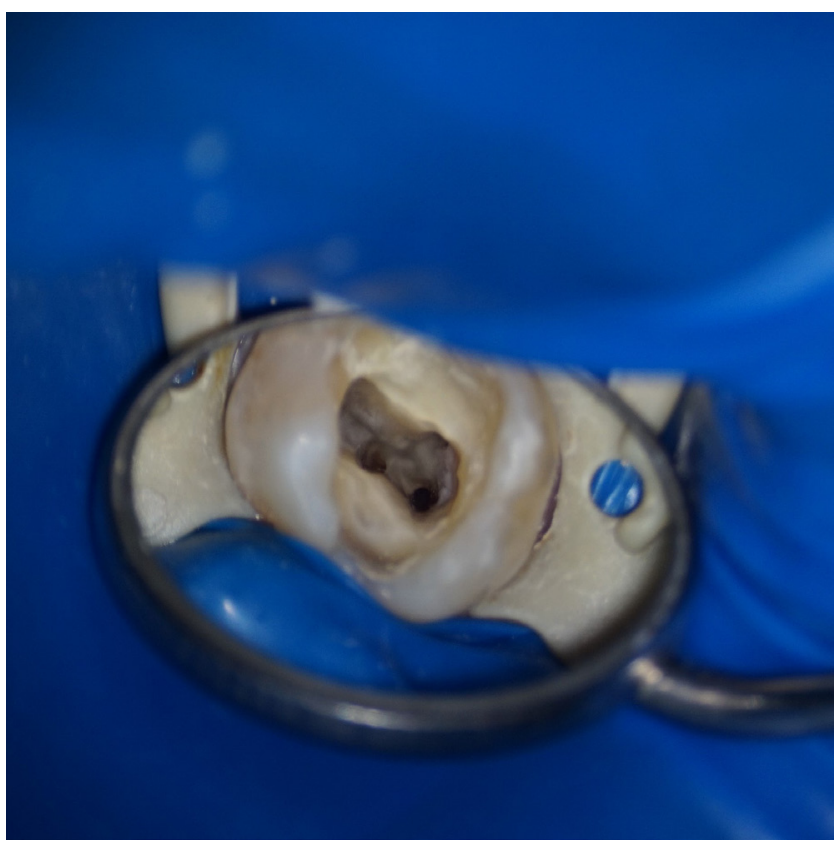

Fig. 1C. Case 1, tooth 27: Microscope-captured images of the pulp chamber floor after denticle removal

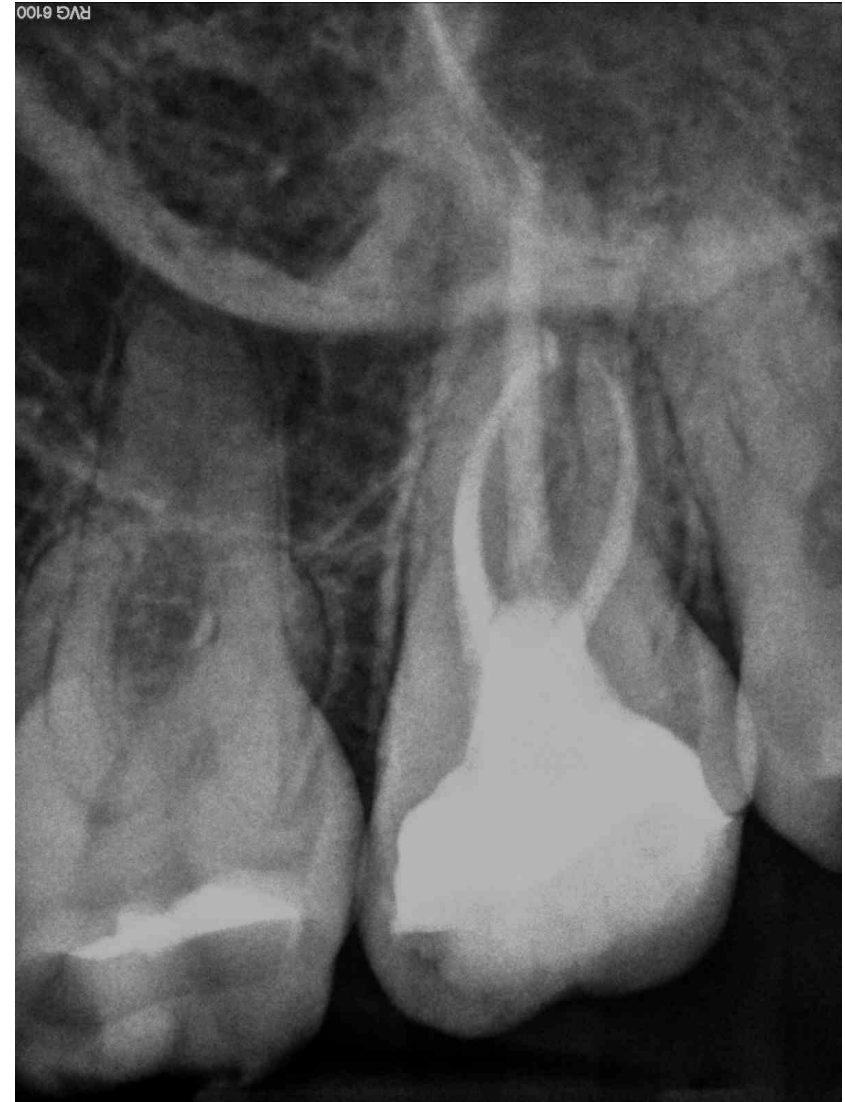

Fig. 1D. Case 1, tooth 27: Post-operative X-ray

\section{Case 2}

A healthy 52-year-old female patient came to the dental office with a referral from a general dental practitioner (GDP) for the specialist RCT of tooth 16 with a diagnosis of calcifications within the pulp and chronic apical periodontitis. The patient made an appointment for the cone-beam computed tomography (CBCT) examination. The clinical examination revealed no pain on percussion, no reaction of the tooth to electrical or thermal stimuli, and physiological mobility. The CBCT scans with sagittal, axial, and coronal views showed an extensive filling on the mesial, distal and occlusal surfaces, the presence of a PS within the pulp cavity (homogenous radiopaque contrast), and a periapical lesion (Fig. $2 \mathrm{~A}-2 \mathrm{C}$ ). The CBCT analysis detected a denticle in the pulp cavity above the orifice of the palatal canal, severe curvature of the buccal canals and chronic apical periodontitis. A diagnosis of chronic granuloma periodontitis was made and antiseptic RCT was arranged. Endodontic treatment with rubber-dam isolation was started. The tooth was trepanned and the pulp cavity was prepared using a dental OM. After the roof of the pulp chamber was removed with a long-shank rose-head bur for a slow-speed handpiece, the presence of an extensive PS blocking the orifice of the palatal canal was confirmed. The preparation of the pulp cavity and the removal of the denticle were carried out with the use 


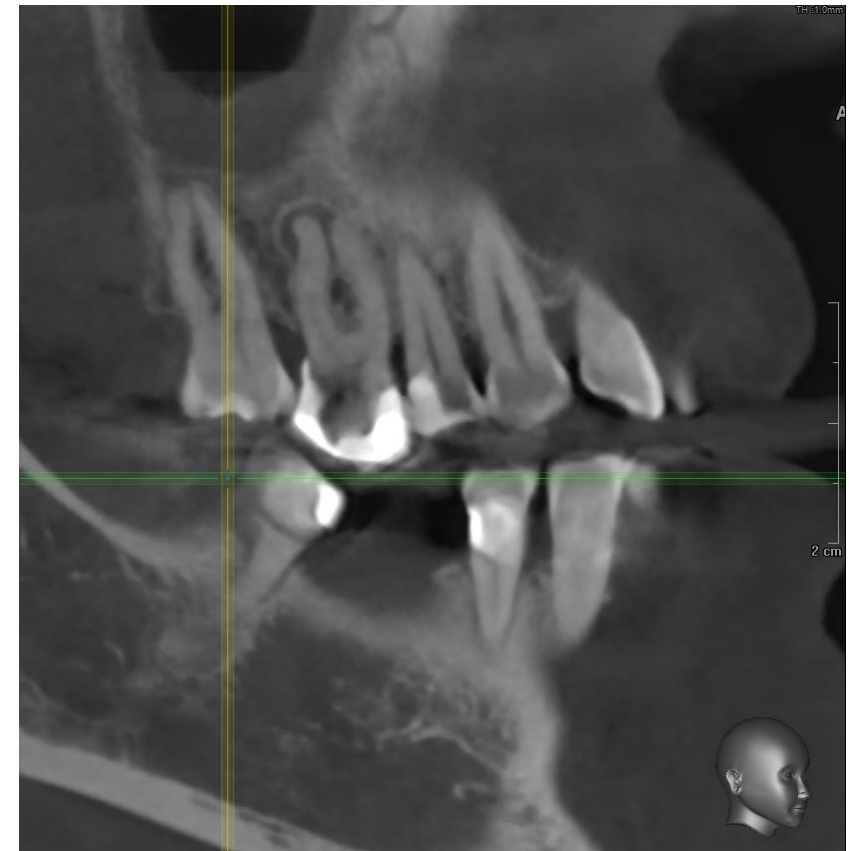

Fig. 2A. Case 2, tooth 16: Cone-beam computed tomography (CBCT) scan with a sagittal view

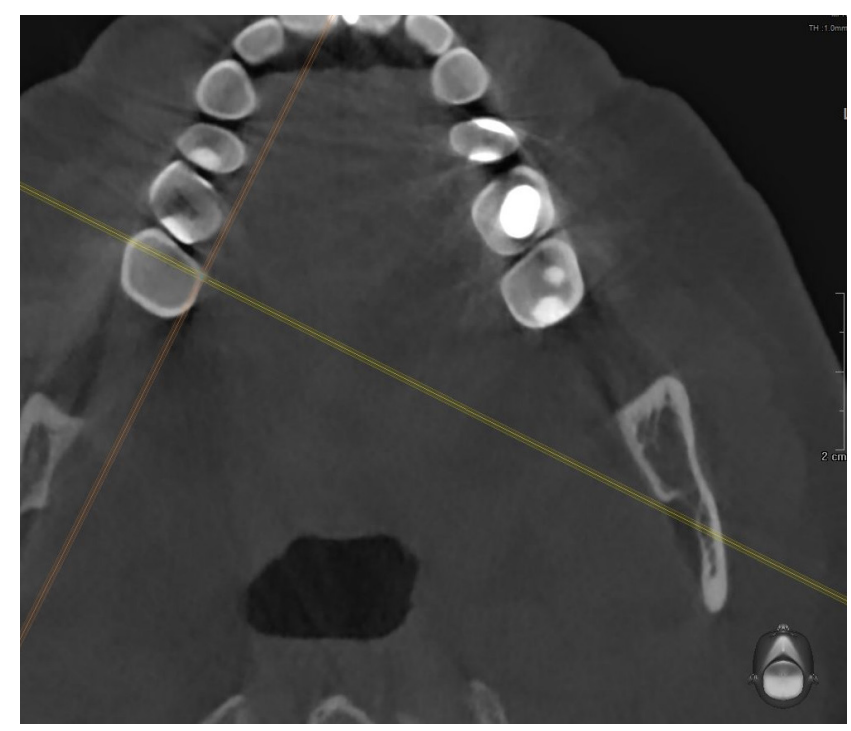

Fig. 2B. Case 2, tooth 16: CBCT scan with an axial view

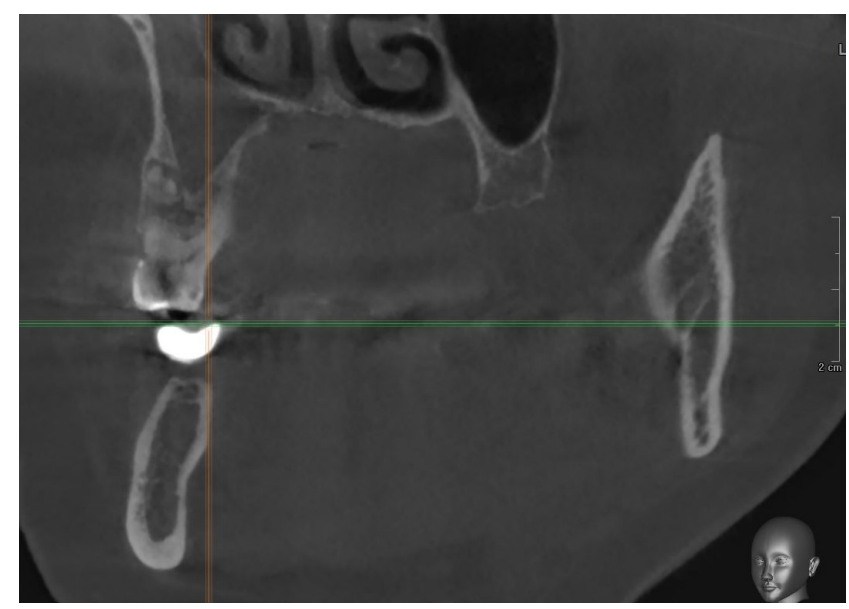

Fig. 2C. Case 2, tooth 16: CBCT scan with a coronal view of the BUC 2 ultrasonic tip (Obtura Spartan) and Munce Discovery Burs No. 1 (CJM Engineering, Inc.). Gates -Glidden drills (Dentsply Sirona) were used to prepare the canal orifices. After determining the working length of all canals with an apex locator, they were initially shaped with the C-Pilot ${ }^{\circledR}$ size 06-10 hand files (VDW) to create a glide path. Due to a lack of time, an antibiotic-steroid dental paste (Dexadent; Chema-Elektromet) and a cotton pledget were inserted, and a Cavit temporary filling was applied (3M ESPE). At the following appointment, the canals were shaped with the ProTaper Next NiTi rotary files (Dentsply Sirona); the last file for all buccal canals was PT X2, size 25.06, and for the palatal canal, PT X3 size 30.07. The rinsing and filling protocol was followed as described above. A control X-ray was taken (Fig. 2D) and the patient was referred to her GDP for the final restoration.

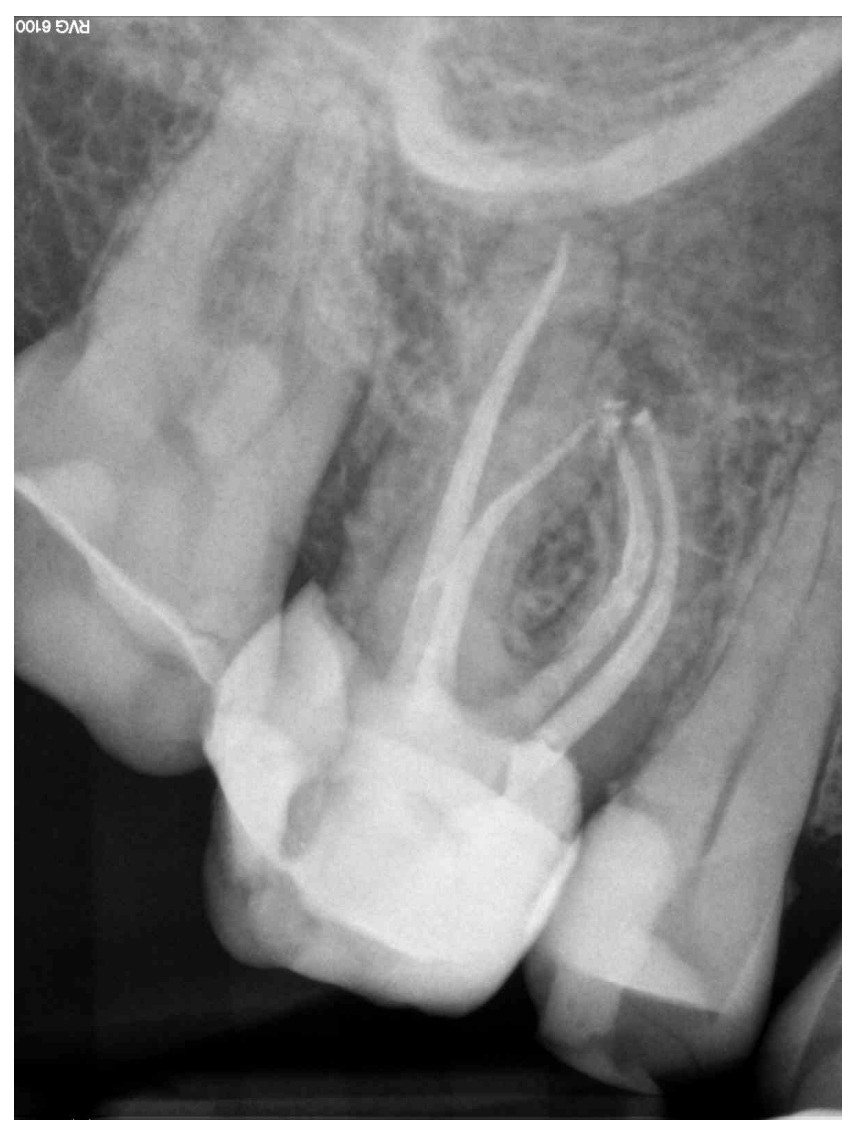

Fig. 2D. Case 2, tooth 16: Post-operative X-ray

\section{Case 3}

A generally healthy patient, aged 57, visited the dental office with spontaneous, long-lasting pain radiating to the ear, characteristic of irreversible pulpitis. The clinical examination of tooth 47 revealed pain on vertical percussion, and a prolonged reaction to electric and thermal stimuli. An initial periapical tooth X-ray was taken. Nonhomogenous radiopaque contrast in the projection of the pulp chamber and the root canals, indicating their partial 
obliteration, were revealed on the X-ray as well as the widening of the periodontal ligament space (Fig. 3A). The tooth was anesthetized with $4 \%$ articaine hydrochloride with adrenaline at 1:100,000. Under rubber-dam isolation, the pulp cavity was trepanned and massive bleeding was observed for a few minutes. After gaining access to the pulp chamber, its roof was removed with a surgical drill with extended handles for a slow-speed handpiece and the canal orifices were located by means of a dental OM. When bleeding stopped, the pulp chamber floor was irrigated with a $5.25 \% \mathrm{NaOCl}$ solution, dried with a cotton pledget, and carefully inspected in order to find color changes that could indicate the way to the canal orifices. The floor of the pulp chamber had a non-homogenous, dark yellow structure varying in shape and size, closing the canal orifices (Fig. 3B). By scouting the pulp cavity floor gently with the C-Pilot instruments (VDW), access to all canal orifices was established. However, shaping the distal canal was problematic due to the obstruction by a PS. For the removal of the radicular pulp stone, 2 Hedström $^{\circledR}$ size 15 files (Kerr Dental, Orange, USA) were used. All canals

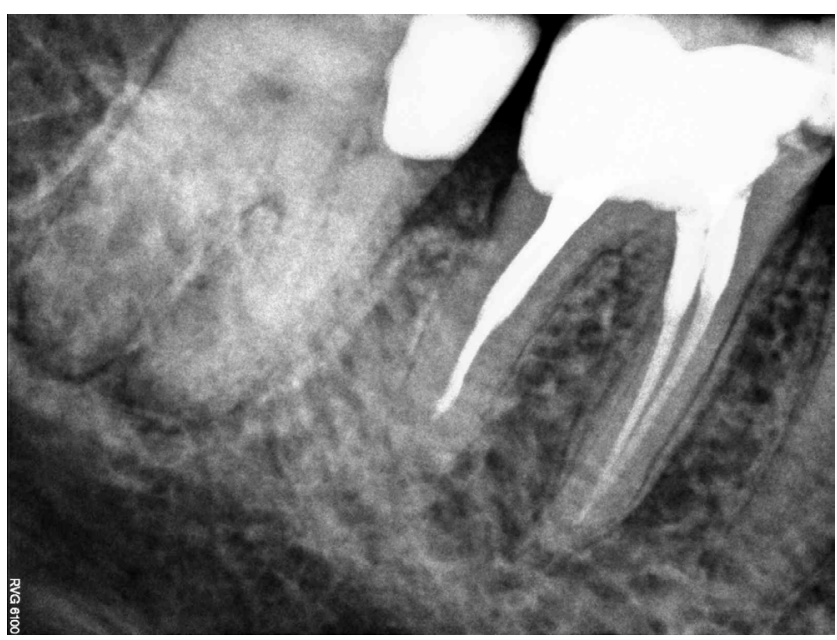

Fig. 3A. Case 3, tooth 47: Pre-operative X-ray

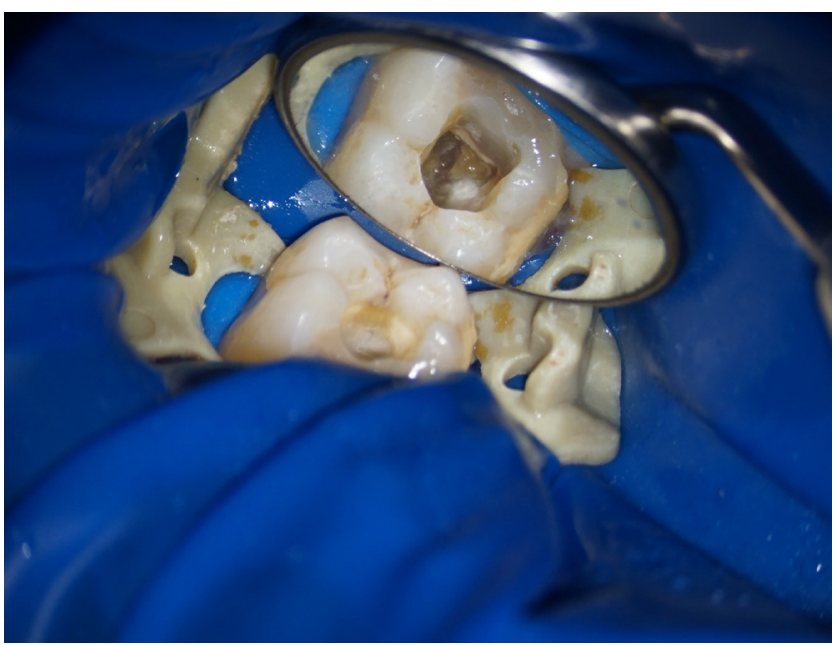

Fig. 3B. Case 3, tooth 47: Microscope-captured image of the pulp chamber floor before denticle removal were cleaned and shaped to full working length according to an apex locator with the Mtwo rotary files (VDW) to size 35/.04 (Fig. 3C). Due to a lack of time, the canals were filled with calcium hydroxide and a sterile cotton pledget, and a Cavit temporary filling was applied (3M ESPE). At the next appointment, all canals were finally obturated. A rinsing and filling protocol was followed as described in the cases above. At the end of RCT, a control X-ray was taken (Fig. 3D). The canals were filled properly and the patient was referred for final reconstruction.

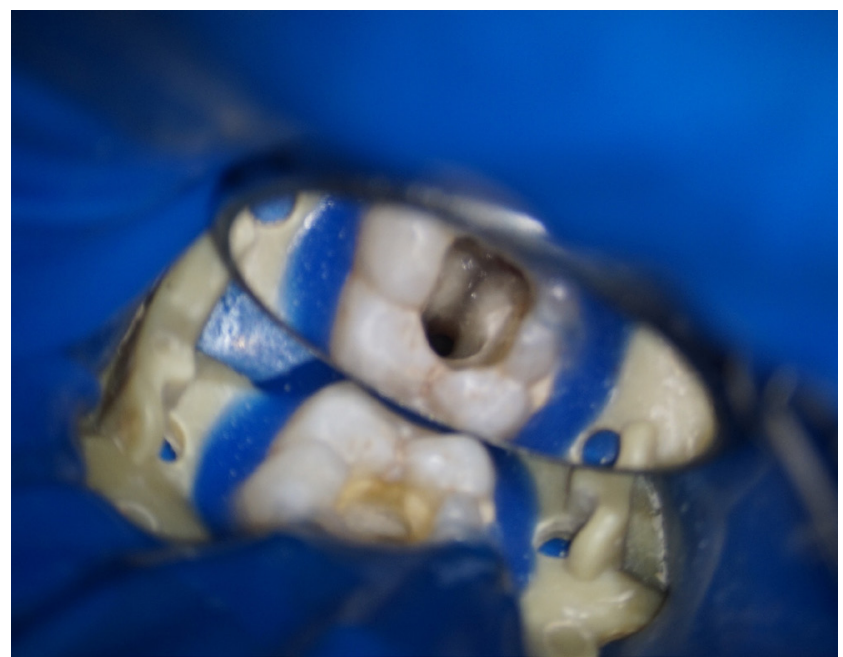

Fig. 3C. Case 3, tooth 47: Microscope-captured image of the pulp chamber floor after denticle removal

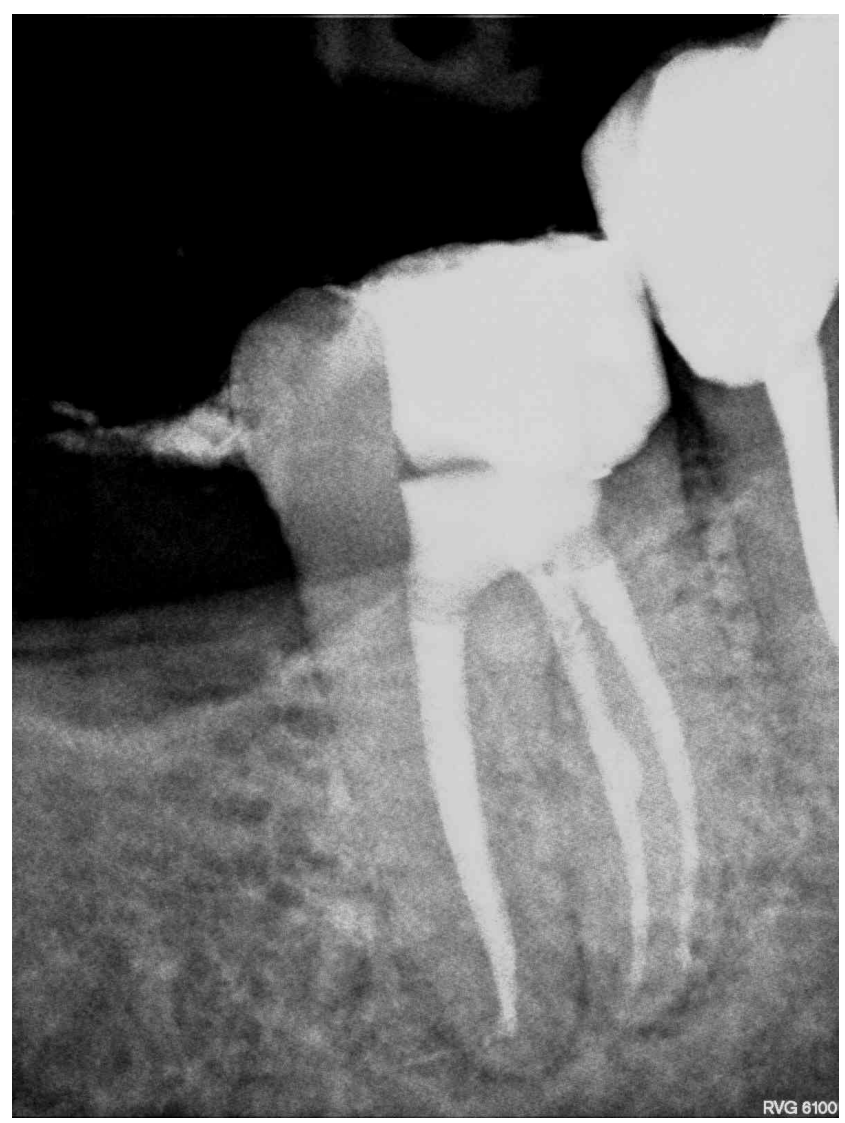

Fig. 3D. Case 3, tooth 47: Post-operative X-ray 


\section{Case 4}

A 38-year-old, generally healthy patient reported to the dental office because of the hypersensitivity to cold of the maxillary teeth on the right side. Tooth 16 was the most sensitive to a cold stimulus (ethyl chloride). Initial RVG was performed and radiopaque contrast within the pulp chamber was noticed, which could indicate the presence of a denticle (Fig. 4A). Infiltration anesthesia with Citocartin ${ }^{\circledR} 100$ (Molteni Dental S.r.l., Milan, Italy) was administered and an amalgam filling was removed from the occlusal surface. At the height of the proximal buccal cusp, the entrance to the pulp cavity was visible. After placing a rubber dam, proper access was prepared and the presence of an extensive calcification with the PS features was visible under a dental OM (Fig. 4B). The Start- $\mathrm{X}^{\circledR}$ ultrasonic tip No. 3 (Dentsply Sirona) was used to remove the denticle. After removing the PS - which loosely filled the pulp chamber - with an endodontic probe (Fig. 4C), the pulp cavity was prepared using surgical drills with extended handles. Due to a lack of time, an antibiotic-steroid dental paste (Dexadent; Chema-Elektromet), a cotton pledget and a Cavit temporary filling (3M ESPE) were inserted. At the next appointment, 4 canal orifices were detected: palatal; mesio-buccal 1; mesio-buccal 2; and disto-buccal. Gates-Glidden drills (Dentsply Sirona) were applied to prepare the canal orifices. After preparing a glide path with hand instruments, the working length was determined with the use of an apex locator and the Mtwo rotary files were used up to No. 30. During the mechanical preparation, $5 \% \mathrm{NaOCl}$ and EDTA irrigation solutions were administrated with ultrasonic activation. All canals were filled with the thermal method of gutta-percha and AH Plus (Dentsply Sirona) as a sealer. The canal orifices were protected by a flowable, colored composite material and the cavity within the tooth crown was filled with Herculite XRV Ultra ${ }^{\circledR}$ (Kerr Dental). Control RVG was performed (Fig. 4D).

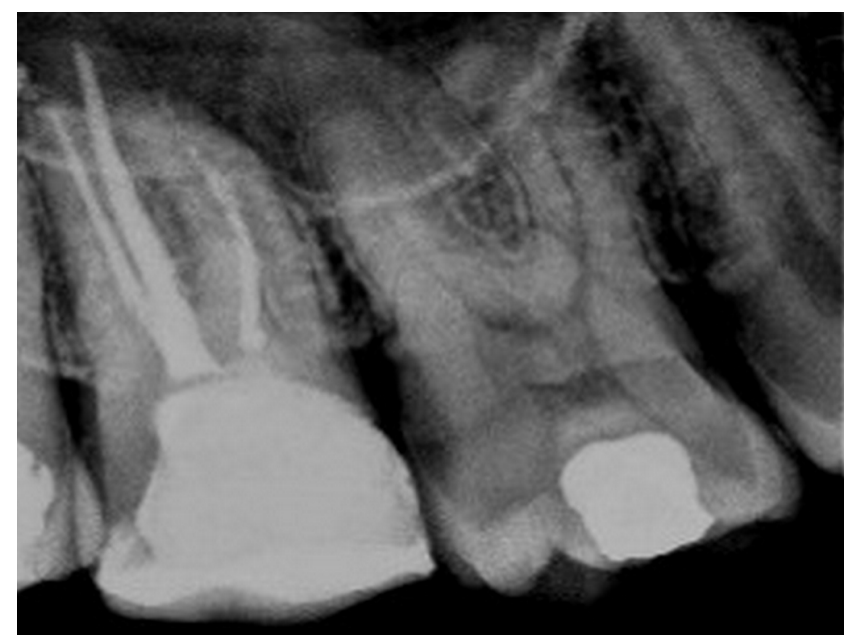

Fig. 4A. Case 4, tooth 16: Pre-operative X-ray

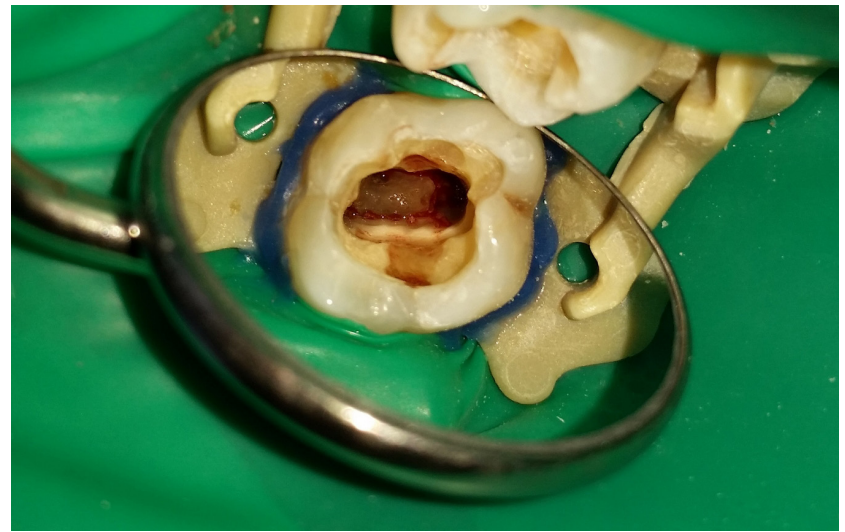

Fig. 4B. Case 4, tooth 16: Microscope-captured images of the pulp chamber floor before denticle removal

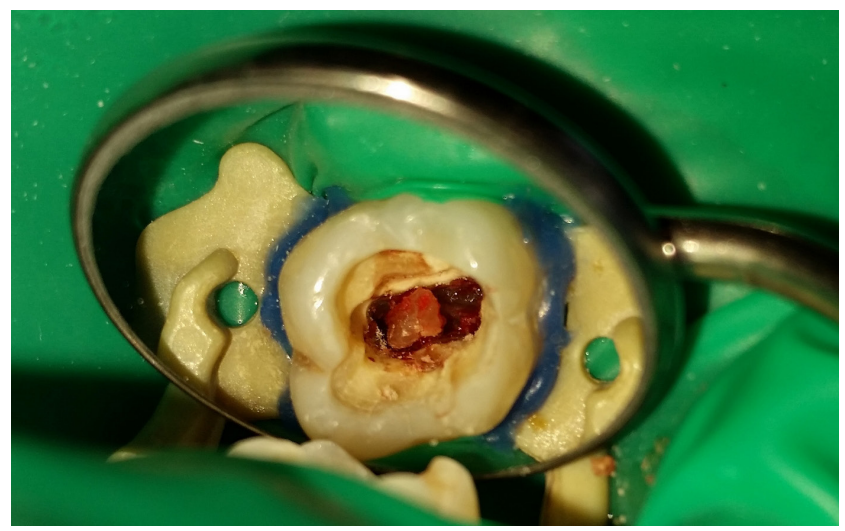

Fig. 4C. Case 4, tooth 16: Microscope-captured images of the pulp chamber floor during denticle removal

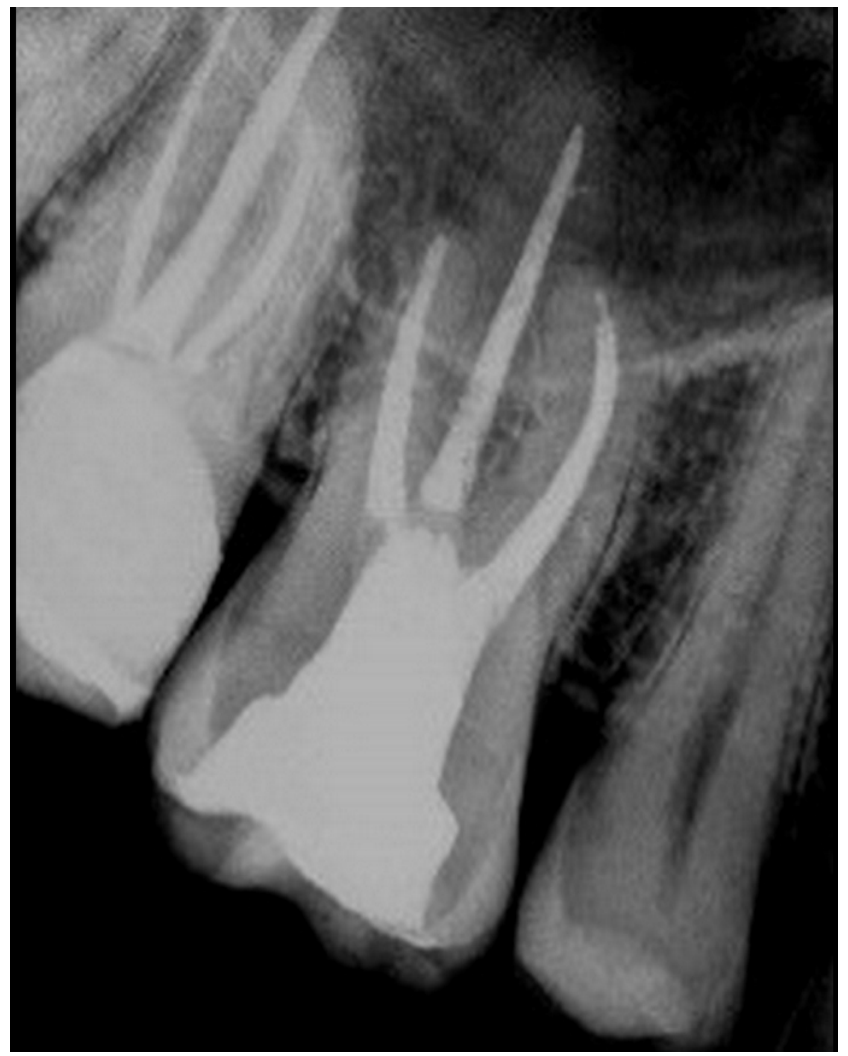

Fig. 4D. Case 4, tooth 16: Post-operative X-ray 


\section{Discussion}

Denticles are foci of calcification in the dental pulp, located mostly in pulp chambers. Denticles differ in size, ranging from microscopic particles to larger masses that nearly obliterate the pulp chamber and are visible on radiographs as dense, radiopaque masses. ${ }^{2-6}$ Although the etiological agents in the formation of pulpal calcifications are not completely understood, the gender and age of the patient, various systemic disorders and long-term irritation, such as deep caries and extensive restorations, have been proposed as possible factors in the formation of PSs. ${ }^{7-10}$ The association of PSs and the age of patients has been assessed by researchers in previous studies. No significant correlation with an increasing age was found in the studies by Aslantas et al. and Kannan et al. ${ }^{13,14}$ This data is in agreement with the present study.

Many prevalence studies have identified PSs using radiography. Pulpal calcifications appear radiographically as dense, radiopaque masses. When the diameter of a PS is smaller than $200 \mu \mathrm{m}$, a diagnosis of denticles cannot be made using dental radiography. The most commonly used radiographic techniques to detect denticles are panoramic radiographs, ${ }^{15}$ intraoral periapical radiographs ${ }^{16}$ and bitewing radiographs. ${ }^{11}$ The $\mathrm{CBCT}$ imaging has also been reported to increase predictability in treating calcified canals. ${ }^{17}$

A small number of studies analyzing the location of denticles in the pulp cavity have been published. ${ }^{15,18,19}$ According to Syryńska et al., denticles occurred in the pulp chambers of $69.4 \%$ of individuals; PSs were found in the canals on only $3.5 \%$ of 165 panoramic radiographs. ${ }^{15}$ This data corresponds with our study, where a radicular stone was described in only 1 case (case 3 ). According to the literature, denticles occur more frequently in the maxillary teeth than in the mandibular teeth. The present study is in accordance with this finding. ${ }^{20,21}$ Nowadays, CBCT is more common in dental practice, as it is helpful in providing precise three-dimensional (3D) images of anatomic details, which are useful for diagnosis and endodontic treatment planning. ${ }^{22}$ The CBCT examination could be an efficient technique in diagnosing and locating denticles and calcified canals. The knowledge of the distribution of PSs can help dental practitioners in clinical endodontic treatment. This diagnostic tool was also applied in case 2 . The removal of PSs from the pulp chamber is a difficult, laborious and time-consuming process, which requires not only skill and dexterity, but also the right equipment and magnification devices. ${ }^{23,24}$ These conditions were fulfilled while treating the teeth described in this study in all cases. At present, the main methods for dealing with root canal calcification include appropriate pre-operative dental radiography, good magnification (a dental OM), instruments such as small $\mathrm{K}$ files or $\mathrm{C}$ files, and ultrasonic equipment with endodontic tips. ${ }^{25}$ Large PSs can be dissected out of the pulp cavity using long-shank rose-head burs for a slow-speed handpiece, but ultrasonic instruments with diamond-coated ultrasonic tips make their removal far easier. The power of an ultrasonic device for the endodontic tips should be set according to the manufacturer's recommendations. Ultrasonic tips can be used with or without water cooling. When used in dry conditions, it is recommended to take several breaks for the irrigation of the pulp cavity with a $\mathrm{NaOCl}$ or EDTA rinsing solution. Denticles in our study were removed from the pulp chamber with Munce Discovery Burs and an ultrasonic device with endodontic tips. In our cases, ultrasonic tips were used without water cooling and with profuse $\mathrm{NaOCl}$ irrigation during the breaks. A similar procedure was presented by Nanjannawar et al., who reported removing denticles with ultrasonic instruments used with copious sodium hypochlorite irrigation. ${ }^{26}$ In their study, long radicular calcifications were finally retrieved from the palatal canals with the help of tweezers. ${ }^{26}$ Recently, a new report on the potential of non-instrumental methods to remove pulpal calcifications was published. Chen et al., in an ex vivo study, evaluated the removal of calcifications with the GentleWave ${ }^{\circledR}$ system using the micro-CT imaging as the method of estimation. ${ }^{27}$ The researchers concluded that calcifications in the distal canals of the mandibular molars could be partially or completely removed by the multisonic cleaning system without instruments. ${ }^{27}$

Severe pulp space calcification is a challenge in cases of periapical lesions. In cases 1 and 2 of this study, with diagnoses of calcifications and apical periodontitis, denticles were successfully removed with the use of elongated rosehead burs and ultrasonic special tips. Unfortunately, in dealing with calcified root canals, the preparation of an access cavity and the identification of the canal orifices may lead to an excessive loss of the tooth tissue, the risk of fracture, and - in consequence - a high failure rate. The dentist must be familiar with the anatomical clues which are helpful in locating calcified canal orifices: the color of the pulp chamber floor is always darker than the yellowish walls, and the root canal orifices are always located at the junction of the walls and the floor. The orifices of the root canals are located at the terminus of the root developmental fusion lines. ${ }^{28}$

Recently, guided endodontics has become an optional solution for cases with severe pulp space calcification. This modern technology is designed to handle pulp canal calcifications in teeth with straight and thin roots with the use of the CBCT scans to map the degree of obliteration and a printed template that guides the bur to the calcified root canal. Micro-guided endodontics provides a precise, fast and operator-independent technique without the unwanted removal of enamel and dentin. ${ }^{29,30}$ Due to the rapid technological progress in dentistry, guided endodontics may become standard in the future and may also be established in endodontic practices.

\section{ORCID iDs}

Krystyna Pietrzycka (D) https://orcid.org/0000-0003-4664-0890 Halina Pawlicka (i) https://orcid.org/0000-0002-0135-0673 


\section{References}

1. Langeland $\mathrm{K}$, Rodrigues $\mathrm{H}$, Dowden W. Periodontal disease, bacteria, and pulpal histopathology. Oral Surg Oral Med Oral Pathol. 1974;37(2):257-270.

2. Kronfeld R, Boyle PE. Histopathology of the Teeth and Their Surrounding Structures. $4^{\text {th }}$ ed. London, UK: Henry Kimpton; 1955.

3. Mahajan P, Monga P, Bahunguna N, Bajaj N. Principles of management of calcified canals. Indian J Dent Sci. 2010;2(Suppl):3-5.

4. Arys A, Philippart C, Dourov N. Microradiography and light microscopy of mineralization in the pulp of undemineralized human primary molars. J Oral Pathol Med. 1993;22(2):49-53.

5. Moss-Salentijn L, Klyvert MH. Epithelially induced denticles in the pulps of recently erupted, noncarious human premolars. J Endod. 1983;9(12):554-560.

6. Goga R, Chandler NP, Oginni AO. Pulp stones: A review. Int Endod J. 2008;41(6):457-468.

7. Bains SK, Bhatia A, Singh HP, Biswal SS, Kanth S, Nalla S. Prevalence of coronal pulp stones and its relation with systemic disorders in northern Indian central punjabi population. ISRN Dent. 2014:2014;617590.

8. Edds AC, Walden JE, Scheetz JP, Goldsmith LJ, Drisko CL, Eleazer PD. Pilot study of correlation of pulp stones with cardiovascular disease. J Endod. 2005;31(7):504-506.

9. Jena D, Balakrishna K, Singh S, Naqvi ZA, Lanje A, Arora N. A retrospective analysis of pulp stones in patients following orthodontic treatment. J Contemp Dent Pract. 2018;19(9):1095-1099.

10. Zeng J, Yang F, Zhang W, Gong Q, Du Y, Ling J. Association between dental pulp stones and calcifying nanoparticles. Int J Nanomedicine. 2011;6:109-118.

11. Ranjitkar S, Taylor JA, Townsend GC. A radiographic assessment of the prevalence of pulp stones in Australians. Aust Dent $J$. 2002;47(1):36-40.

12. Moss-Salentijn L, Hendricks-Klyvert M. Calcified structures in human dental pulps. J Endod. 1988;14(4):184-189.

13. Aslantas EE, Buzoglu HD, Karapinar SP, et al. Age-related changes in the alkaline phosphatase activity of healthy and inflamed human dental pulp. J Endod. 2016;42(1):131-134.

14. Kannan S, Kannepady SK, Muthu K, Jeevan MB, Thapasum A. Radiographic assessment of the prevalence of pulp stones in Malaysians. J Endod. 2015;41(3):333-337.

15. Syryńska M, Durka-Zajac M, Janiszewska-Olszowska J. Prevalence and location of denticles on panoramic radiographs. Ann Acad Med Stetin. 2010;56(2):55-57.

16. Gulsahi A, Cebeci Al, Ozden S. A radiographic assessment of the prevalence of pulp stones in a group of Turkish dental patients. Int Endod J. 2009;42(8):735-739.

17. Patel S, Durack C, Abella F, Shemesh H, Roig M, Lemberg K. Cone beam computed tomography in endodontics - a review. Int Endod J. 2015;48(1):3-15.

18. Rodakowska E, Ochnio A, Struniawska A. Not to be forgotten: Denticles. Case reports and review of the literature. Ann Acad Med Stetin. 2011;57(3):77-81.

19. Udoye $\mathrm{Cl}$, Sede MA. Prevalence and analysis of factors related to occurrence of pulp stone in adult restorative patients. Ann Med Health Sci Res. 2011;1(1):9-14.

20. Hsieh CY, Wu YC, Su CC, et al. The prevalence and distribution of radiopaque, calcified pulp stones: A cone-beam computed tomography study in a northern Taiwanese population. J Dent Sci. 2018;13(2):138-144.

21. Nogueira Leal da Silva EJ, Prado MC, Queiroz PM, et al. Assessing pulp stones by cone-beam computed tomography. Clin Oral Investig. 2017;21(7):2327-2333.

22. Patel S, Brown J, Pimentel T, Kelly RD, Abella F, Durack C. Cone beam computed tomography in endodontics - a review of the literature. Int Endod J. 2019;52(8):1138-1152.

23. Olczak K, Kabacińska K, Pawlicka H. Management of pulp canal obliterations. Czas Stomatol. 2017;70(5):597-612.

24. Palatyńska-Ulatowska A, Pietrzycka K, Koprowicz A. Denticles of the pulp chamber - diagnostics and management. Case studies. Pomeranian J Life Sci. 2019;65(2):29-36.
25. Freedman G, Glassman G. Buyers' guide to endodontic equipment. An in-depth look at today's apex locators, obturation systems, and ultrasonic systems. Dent Today. 2009;28(4):118,120,122 passim.

26. Nanjannawar GS, Vagarali H, Nanjannawar LG, Prathasarathy B, Patil A, Bhandi S. Pulp stone - an endodontic challenge: Successful retrieval of exceptionally long pulp stones measuring 14 and $9.5 \mathrm{~mm}$ from the palatal roots of maxillary molars. J Contemp Dent Pract. 2012;13(5):719-722.

27. Chen B, Szabo D, Shen $Y$, et al. Removal of calcifications from distal canals of mandibular molars by a non-instrumentational cleaning system: A micro-CT study. Aust Endod J. 2019 [Epub]. doi: 10.1111/ aej.12376

28. Krasner P, Rankow HJ. Anatomy of the pulp-chamber floor. J Endod. 2004;30(1):5-16.

29. Connert T, Zehnder MS, Amato M, Weiger R, Kühl S, Krastl G. Microguided endodontics: A method to achieve minimally invasive access cavity preparation and root canal location in mandibular incisors using a novel computer-guided technique. Int Endod J. 2018;51(2):247-255.

30. Moreira Maia L, de Carvalho Machado V, Alves da Silva NRF, et al. Case reports in maxillary posterior teeth by guided endodontic access. J Endod. 2019;45(2):214-218. 